\title{
Police Killings of Unarmed Black Americans: A Reassessment of Community Mental Health Spillover Effects *
}

\author{
Justin Nix University of Nebraska Omaha \\ M. James Lozada Vanderbilt University Medical Center
}

We reevaluate the claim from Bor et al. (2018) that "police killings of unarmed black Americans have effects on mental health among black American adults in the general population" (p. 302). The Mapping Police Violence data used by the authors includes 91 incidents involving black decedents who were either (1) not killed by police officers in the line of duty or (2) armed when killed. These incidents should have been removed or recoded prior to analysis. Correctly recoding these incidents decreased in magnitude all of the reported coefficients, and, more importantly, eliminated the reported statistically significant effect of exposure to police killings of unarmed black individuals on the mental health of black Americans in the general population. We caution researchers to vet carefully crowdsourced data that tracks police behaviors and warn against reducing these complex incidents to overly simplistic armed/unarmed dichotomies.

Keywords: policing, mental health, deadly force, data validity

\section{Introduction}

In their study "Police Killings and their Spillover Effects on the Mental Health of Black Americans," Bor et al. (2018) employed a quasi-experimental design to show that, from 2013 to 2016, "each additional police killing of an unarmed black American was associated with 0.14 additional poor mental health days among black American respondents [to the US Behavioral Risk Factor Surveillance System]" (p. 302). They extrapolate from this that police killings of unarmed black Americans may cause as many as 55 million poor mental health days each year among black adults in the US, an effect "nearly as large as the mental health burden associated with diabetes" (p. 308). The study has received extensive scholarly, media, and social media attention. Published in The Lancet, one of the oldest and most prestigious medical journals in the world (with an Impact Factor of 59.1 in 2018), the study has been cited 184 times as of December 10, 2020. It received the highest "quality assessment" score among 11 studies included in a recent systematic review of evidence concerning the relationship between police interactions and the mental health of black Americans (McLeod et al., 2020). It has also received 193 news mentions (including Washington Post, USA

*This is the authors' post-print (CC BY-NC-ND 4.0). Final version published in Police Practice $\boldsymbol{E}$ Research. (Accepted 1/15/2021). Corresponding author: jnix@unomaha.edu. 
Today, US News $\&$ World Report, VICE, and WIRED) and been referenced in over 2,500 Twitter interactions according to PlumX Metrics. ${ }^{1}$

Bor et al.'s data on police killings were compiled by Mapping Police Violence (MPV), a research collaborative operated by a team of racial justice activists. The research team sourced the data from FatalEncounters.org, the U.S. Police Shootings Database, and KilledbyPolice.net, and then sought supplementary information (e.g., searching social media, obituaries, criminal records databases, police reports) to document additional details about each incident. ${ }^{2}$ We first expressed concern about how MPV classifies police killings in correspondence published alongside Bor and colleagues' study (Lozada \& Nix, 2019). Specifically, we noted that MPV classifies many incidents as involving "unarmed" individuals when in fact they were in possession of deadly weapons or toy guns that might have appeared authentic to officers. Bor et al. (2019) were dismissive, stating "[a]lthough some degree of misclassification of exposure is possible, it is improbable to have substantially affected our estimates or conclusions" (p. 1413). They also referenced the police shooting of 12year-old Tamir Rice, seemingly holding it up as evidence that for their research question it was not necessary to distinguish police killings of unarmed individuals from those of individuals armed with toy guns. Shockingly, the authors opted not to revisit their data or verify the robustness of their findings. ${ }^{3}$

In December 2019, Science Advances published a paper which employed a similar methodology and purported to show a causal relationship between exposure to police killings of unarmed black persons and low birth weight among black infants in California (Legewie, 2019). Within eight days, the author retracted the paper. A reader had identified numerous shootings that were misclassified as involving unarmed persons, and when the author promptly investigated and re-ran his statistical models, he could not replicate his primary finding (American Association for the Advancement of Science and others, 2019). Seeing how this unfolded, we grew concerned that the same could be true of Bor et al. (2018).

\footnotetext{
${ }^{1}$ See https://plu.mx/plum/a/?doi=10.1016/S0140-6736(18)31130-9.

${ }^{2}$ See https://mappingpoliceviolence.org/aboutthedata.

${ }^{3}$ Eventually, Bor et al. (2020) responded to the analyses we present in this paper by estimating 128 regression models "reflecting all of the different exposure terms constructed from all combinations of omissions of the 7 categories of cases" (see p. 6) that we dispute here. All point estimates were positive, though notably, $39 \%$ were statistically non-significant. More important, their approach implies that all 128 combinations had construct validity. Many did not, as we discuss below.
} 


\section{Analysis and Results}

We reexamined all 303 police killings occurring from 2013 to 2016 which MPV classified as involving an unarmed black victim. MPV defines police killings as "case[s] where a person dies as a result of being chased, beaten, arrested, restrained, shot, pepper sprayed, tasered, or otherwise harmed by police officers, whether on-duty or off-duty, intentional or accidental." This is an extremely broad definition, and indeed we identified 91 incidents (30\% of all "unarmed black victims") that should have been removed or recoded prior to Bor et al.'s analysis. Table 1 summarizes these misclassifications. Details for each incident are provided in Appendix A.

[Table 1 here]

First, 52 of Bor et al.'s "unarmed black victims" were not killed intentionally by on-duty police officers. Seventeen died in vehicular crashes while fleeing officers. Another four died not while fleeing, but as a result of accidental vehicular collisions with police cruisers. Four were prison inmates who died after fighting with other inmates or fighting with/being restrained by prison guards (i.e., not police officers). Fourteen were murdered by romantic partners, family members, friends, neighbors, or other individuals who were off-duty police or correctional officers. Finally, thirteen died following interactions with police officers, but their deaths were not directly attributable to police intervention. Sandra Bland, for example, committed suicide in a Texas jail three days after her arrest (Dart, 2015). All 52 of these incidents should have been removed from Bor et al.'s analysis.

Another 13 individuals were killed intentionally by police officers in the line of duty but should not have been classified as "unarmed." For example, body camera footage shows Jason Harrison advance toward two Dallas police officers at close range with a screwdriver in-hand just before the officers shot him (Tsiaperas, 2016). Others tried to run over police officers with their vehicles or nearly gained control of their service firearms while resisting arrest. These incidents should have been coded as "armed" in Bor et al.'s analysis.

Finally, it is problematic to lump together police killings of unarmed individuals with those of individuals who were in possession of toy/replica firearms or objects that might reasonably resemble deadly weapons to officers in the moment. There were 26 such incidents included in Bor et al.'s analysis. Consider the police shootings of 21-year-old Donovan Thomas in Missouri, or 27-year-old 
Willie James Williams in Georgia - both of whom were robbery suspects armed with BB guns that resembled real pistols. It is disingenuous to equate incidents like these with police killings of individuals who neither had a weapon nor anything resembling a weapon. However, as Bor et al. (2019) point out, such a distinction may not be necessary when considering the potential spillover effect of police killings on the mental health of the general population. Accordingly, the most reasonable analytic strategy is to analyze the data with these 26 individuals coded as unarmed and then again with the same individuals coded as armed. In this way, the authors could check whether their findings are sensitive to the coding of these controversial incidents.

We recalculated Bor et al. (2018)'s models predicting their primary outcome, poor mental health days, as well as their secondary outcomes, any poor mental health days and frequent mental distress, using the corrected data. The results are displayed in Table 2 (primary outcome) and Table 3 (secondary outcomes). The authors' original results are listed in the first column of each table, which we were successfully able to replicate using the data and code they deposited online (Venkataramani, 2018). The second column of each table (Replication 1) provides results of the same analysis with the 52 incidents involving individuals not intentionally killed by on-duty police officers dropped and the 13 decedents wrongly coded as "unarmed" corrected to "armed." In the third column of each table (Replication 2), we re-coded an additional 26 individuals in possession of toy guns or objects that reasonably resembled deadly weapons as "armed."

[Tables 2 and 3 here]

Using the corrected data, we failed to replicate any of the results presented in Bor et al. (2018). Effects were much smaller in magnitude and not statistically significant. Notably, this was the case regardless of how we coded incidents involving individuals who possessed toy guns or objects that may have resembled deadly weapons. In other words, even accepting at face value the assumption that these incidents are perceived by the community as injustices on par with police killings of unarmed individuals, there was not a statistically significant relationship between police killings of unarmed black persons and the mental health of black Americans. 


\section{Conclusion}

Bor et al.'s data, when correctly coded, do not support their conclusion that police killings of unarmed black persons have "spillover effects" on the mental health of black Americans in the general population. This was a landmark study, as it was the first to our knowledge that alleged to demonstrate a causal relationship between "events widely perceived to reflect structural racism and the mental health of black Americans" (p. 308). Since its publication, additional studies - also relying heavily on crowdsourced data - have examined whether police killings of black Americans are associated with other adverse health effects, including sexually transmitted diseases (Ibragimov et al., 2020), preterm birth (Goin, 2019), and lower birth weight (Legewie, 2019; American Association for the Advancement of Science and others, 2019). As this important area of study grows, researchers are challenged with navigating multiple databases that define police killings variably.

In light of our findings, we conclude with two points. First, researchers must exercise caution when analyzing crowdsourced data on police killings - especially data compiled by activists who may not view these incidents through an objective lens. Indeed, even the Pulitzer Prize winning "Fatal Force" database compiled by The Washington Post has been criticized for miscoding armed individuals as unarmed (Klinger \& Slocum, 2017). At the very least, researchers must be attentive to the language they use in light of the data they analyze. As but one example, it was inappropriate for Bor and colleagues to claim in their Introduction that "police kill more than 300 black Americans - at least a quarter of them unarmed - each year in the USA" (p. 302, emphasis added), given there were many incidents in the data involving accidental deaths, deaths at the hands of nonpolice officers (or romantic partners/family members/neighbors who were off-duty police officers), and individuals who were in fact armed.

Second, we must refrain from reducing deaths at the hands of police to whether the person was armed or unarmed, as if this alone is a measure of the appropriateness of officer actions (Fyfe, 1986). Sometimes, officers appropriately use less-lethal force on individuals who die unexpectedly, as was the case when an officer tased Dominique Franklin, Jr., who then hit his head on a light pole and fell, and later died at the hospital (Sege, 2014). In Ohio, officers tased James Carney III who had been punching, choking, and biting a woman while trying to rob her at an ATM. He became unresponsive and later died (Brennan \& Butts, 2015). Both of these individuals were treated as 
unarmed black men killed by police officers in MPV. We opted not to recode these incidents since both deaths stemmed directly from the actions of on-duty police officers. But these incidents were hardly as egregious as the police-involved deaths of Eric Garner and Walter Scott, both of whom Bor and colleagues referenced in the first sentence of their article.

Other times, officers use deadly force on individuals who are not in possession of a deadly weapon, but who nevertheless pose an imminent threat to their safety or the safety of others. For example, Kobvey Igbuhay, an 18-year-old Asian male, was unarmed when Officer Jimmy Houston shot him. Yet, in the moments before he was fatally shot, Igbuhay attempted to drown both Officer Houston and his K9 partner (Sampson, 2015). Given the complexity of these incidents, public health and medical researchers should strongly consider involving policing scholars on projects that examine police shootings. Such collaborations could yield insight into the nuances of data and how they should be interpreted.

Deaths from police intervention are extremely rare - there are roughly 1,000 of them each year in the context of tens of millions of police-civilian interactions (Hyland et al., 2015; Tregle et al., 2019). It is far more common for officers to take armed/dangerous individuals into custody without using deadly force (Wheeler et al., 2018; Worrall et al., 2018). It is absolutely necessary to study the potential public health effects of police intervention. Yet, focusing on extremely rare incidents and reducing them to an overly-simplistic dichotomy may diminish police legitimacy in the eyes of the public, reduce police morale, and hinder our understanding of the structural conditions we hope to improve. 


\section{References}

American Association for the Advancement of Science and others. (2019). Retraction of the research article:"Police violence and the health of black infants".

Bor, J., Venkataramani, A. S., Williams, D. R., \& Tsai, A. C. (2018). Police killings and their spillover effects on the mental health of black americans: A population-based, quasi-experimental study. The Lancet, 392(10144), 302-310.

Bor, J., Venkataramani, A. S., Williams, D. R., \& Tsai, A. C. (2019). Validity of details in databases logging police killings-authors' reply. The Lancet, 393(10179), 1413.

Bor, J., Venkataramani, A. S., Williams, D. R., \& Tsai, A. C. (2020). Reply to: Nix and Lozada (2020), "do police killings of unarmed persons really have spillover effects? Reanalyzing Bor et al. (2018)" [Available at SocArxiv]. https://doi.org/10.31235/osf.io/h6y5w

Brennan, P., \& Butts, R. (2015). Robbery suspect shocked twice with Taser before he died. Cincinnati Enquirer. https://www.cincinnati.com/story/news/2015/09/01/police-man-dies--otrofficer-involved-tasing/71501866/

Dart, T. (2015). Nothing in Sandra Bland autopsy suggests homicide, Texas official says. The Guardian. https://www.theguardian.com/us-news/2015/jul/23/sandra-bland-autopsyhomicide-texas

Fyfe, J. (1986). The split-second syndrome and other determinants of police violence. In A. Campbell \& J. Gibbs (Eds.). Basil Blackwell.

Goin, D. (2019). Community violence and pregnancy: An understudied exposure in the etiology of adverse birth outcomes (Doctoral dissertation). UC Berkeley.

Hyland, S., Langston, L., \& Davis, E. (2015). Police use of nonfatal force, 2002-11 (NCJ 249216). Bureau of Justice Statistics. https://www.bjs.gov/content/pub/pdf/punf0211.pdf

Ibragimov, U., Beane, S., Friedman, S. R., Smith, J. C., Tempalski, B., Williams, L., Adimora, A. A., Wingood, G. M., McKetta, S., Stall, R. D., et al. (2020). Police killings of Black people and rates of sexually transmitted infections: A cross-sectional analysis of 75 large US metropolitan areas, 2016. Sexually Transmitted Infections, 96(6), 429-431.

Klinger, D. A., \& Slocum, L. A. (2017). Critical assessment of an analysis of a journalistic compendium of citizens killed by police gunfire. Criminology \& Public Policy, 16, 349.

Legewie, J. (2019). Police violence and the health of black infants. Science advances, 5(12), eaax7894.

Lozada, M. J., \& Nix, J. (2019). Validity of details in databases logging police killings. The Lancet, $393(10179), 1412-1413$.

McLeod, M. N., Heller, D., Manze, M. G., \& Echeverria, S. E. (2020). Police interactions and the mental health of Black Americans: A systematic review. Journal of Racial and Ethnic Health Disparities, 7(1), 10-27.

Sampson, Z. (2015). Teen fatally shot by Tampa police officer following chase in stolen SUV. Tampa Bay Times. https://www.tampabay.com/news/publicsafety/crime/one-suspect-shot-twoin-custody-and-tampa-police-hunting-for-a-fourth/2251265/

Sege, A. (2014). Man dies after Chicago police use Taser during arrest. Chicago Tribune. https: / / www . chicagotribune. com / news / breaking / chi- man- tased- by- police- while- resistingarrest-dies-20140521-story.html

Tregle, B., Nix, J., \& Alpert, G. P. (2019). Disparity does not mean bias: Making sense of observed racial disparities in fatal officer-involved shootings with multiple benchmarks. Journal of crime and justice, 42(1), 18-31.

Tsiaperas, T. (2016). Federal judge drops civil suit against police officers in shooting death of mentally ill man. The Dallas Morning News. https://www.dallasnews.com/news/crime/ 
2016 / 03 / 14 / federal-judge-drops- civil-suit- against- police- officers-in-shooting- death- ofmentally-ill-man/

Venkataramani, A. (2018). Replication data and code for: Bor et al "Police killings and their spillover effects on mental health among black americans in the US". https://doi.org/10. 7910/DVN/VGYI0E

Wheeler, A. P., Phillips, S. W., Worrall, J. L., \& Bishopp, S. A. (2018). What factors influence an officer's decision to shoot? The promise and limitations of using public data. Justice Research and Policy, 18(1), 48-76.

Worrall, J. L., Bishopp, S. A., Zinser, S. C., Wheeler, A. P., \& Phillips, S. W. (2018). Exploring bias in police shooting decisions with real shoot/don't shoot cases. Crime $\&$ Delinquency, $64(9), 1171-1192$. 
Table 1. Summary of incidents misclassified as involving "unarmed black victims" who were killed by police.

\begin{tabular}{lcc}
\hline Explanation of Misclassification & $N$ & Correction \\
\hline Crashed and died while fleeing police officers & 17 & Drop \\
Accidental vehicular collision with police cruiser & 4 & Drop \\
Died in prison & 4 & Drop \\
Murder/manslaughter by off-duty police or correctional officer & 14 & Drop \\
Died for reasons not directly attributed to police actions & 13 & Drop \\
Armed or attempted to grab police firearm & 13 & Recode as "armed" \\
In possession of toy gun or other object that reasonably & 26 & Recode as "armed" \\
resembled a weapon & & \\
\hline Total & 91 & \\
\hline
\end{tabular}


Table 2. Exposure to police killings of unarmed black Americans and poor mental health days among black Americans (Primary Outcome).

\begin{tabular}{|c|c|c|c|c|c|c|}
\hline \multirow[b]{3}{*}{ Exposure Variable } & \multicolumn{6}{|c|}{ Outcome: Poor Mental Health Days } \\
\hline & \multicolumn{2}{|c|}{ Bor et al. (2018) ${ }^{a}$} & \multicolumn{2}{|c|}{ Replication $1^{\mathrm{b}}$} & \multicolumn{2}{|c|}{ Replication $2^{\mathrm{c}}$} \\
\hline & OLS, Rate Diff. & Poisson, RR & OLS, Rate Diff. & Poisson, RR & OLS, Rate Diff. & Poisson, RR \\
\hline \# of police killings of unarmed & .14 & 1.033 & .04 & 1.010 & .09 & 1.021 \\
\hline black Americans & $(.07-.22)$ & $(1.016-1.051)$ & $(-.06-.15)$ & $(.987-1.034)$ & $(-.03-.20)$ & $(.996-1.047)$ \\
\hline $\mathrm{p}$ value & .00047 & .00011 & .397 & .392 & .124 & .099 \\
\hline Any police killings of unarmed & .35 & 1.087 & .21 & 1.051 & .21 & 1.052 \\
\hline black Americans (vs. none) & $(.03-.67)$ & $(1.006-1.174)$ & $(-.15-.57)$ & $(.964-1.146)$ & $(-.12-.54)$ & $(.972-1.138)$ \\
\hline $\mathrm{p}$ value & .032 & .035 & .250 & .256 & .204 & .209 \\
\hline
\end{tabular}

NOTE: $95 \%$ CIs adjusted for clustering at the state level are displayed in parentheses.

a As reported on p. 306 in Table 3 (columns 1-2).

b Upon removing 52 decedents not killed intentionally by on-duty police officers and recoding 13 who were armed or attempted to gain control of an officer's firearm.

${ }^{c}$ Upon additionally recoding 26 decedents who had a toy/replica firearm and 2 who had an item that could have reasonably resembled a deadly weapon. 
Table 3. Exposure to police killings of unarmed black Americans and poor mental health days among black Americans (Secondary Outcomes).

\begin{tabular}{|c|c|c|c|c|c|c|}
\hline \multirow[b]{2}{*}{ Exposure Variable } & \multicolumn{2}{|c|}{ Bor et al. (2018) ${ }^{a}$} & \multicolumn{2}{|c|}{ Replication $1^{\mathrm{b}}$} & \multicolumn{2}{|c|}{ Replication $2^{\mathrm{c}}$} \\
\hline & $\begin{array}{c}\text { Any poor } \\
\text { mental health } \\
\text { days }\end{array}$ & $\begin{array}{l}\text { Frequent } \\
\text { mental } \\
\text { distress }\end{array}$ & $\begin{array}{c}\text { Any poor } \\
\text { mental health } \\
\text { days }\end{array}$ & $\begin{array}{l}\text { Frequent } \\
\text { mental } \\
\text { distress }\end{array}$ & $\begin{array}{c}\text { Any poor } \\
\text { mental health } \\
\text { days }\end{array}$ & $\begin{array}{l}\text { Frequent } \\
\text { mental } \\
\text { distress }\end{array}$ \\
\hline \# of police killings of unarmed & 1.022 & 1.036 & 1.006 & 1.012 & 1.012 & 1.023 \\
\hline black Americans & $(1.008-1.036)$ & $(1.007-1.068)$ & $(.988-1.024)$ & $(.977-1.048)$ & $(.993-1.032)$ & $(.986-1.062)$ \\
\hline $\mathrm{p}$ value & .0018 & .016 & .503 & .517 & .211 & .222 \\
\hline Any police killings of unarmed & 1.055 & 1.106 & 1.015 & 1.052 & 1.017 & 1.052 \\
\hline black Americans (vs. none) & $(1.007-1.106)$ & $(.986-1.240)$ & $(.965-1.067)$ & $(.945-1.170)$ & $(.972-1.064)$ & $(.954-1.160)$ \\
\hline $\mathrm{p}$ value & .024 & .085 & .574 & .354 & .470 & .306 \\
\hline
\end{tabular}

NOTE: Poisson models are displayed. Entries are risk ratios with 95\% CIs adjusted for clustering at the state level in parentheses.

${ }^{a}$ As reported on p. 306 in Table 3 (columns 3-4).

b Upon removing 52 decedents not killed intentionally by on-duty police officers and recoding 13 who were armed or attempted to gain control of an officer's firearm.

c Upon additionally recoding 26 decedents who had a toy/replica firearm and 2 who had an item that could have reasonably resembled a deadly weapon. 


\section{Appendix A: 91 Misclassified incidents in Bor et al. (2018)}

\section{Crashed and Died While Fleeing Police Officers $(\mathrm{N}=17)$}

Alphonzo Lamonte

Porter Jr.

Amir Brooks

Asia Roundtree

Cornell Gilbert

Devell Johns

Donovan King

Gregory Daquan Harris

Kameron Jackson

Lashonda Ruth Belk

Lavoy Steed

Leon Haywood

Michelle Jenkins

Patrelle J. Stokes

Shiateria Wimbash

Syiid Brinkley

Trevor Tyreke

Chambers

Wally Flex
Passenger in a car that crashed while fleeing police officers

Fled officers on his dirt bike and crashed

Passenger in a car that crashed into a tree while fleeing police officers

Passenger in a stolen car that struck a pole while fleeing police officers

Crashed into a jeep while fleeing police officers

Passenger in a car that crashed while fleeing police officers

Passenger in a car that crashed on a curve while fleeing police officers

Passenger in a car that crashed while fleeing police officers

Passenger in a car that crashed on a curve while fleeing police officers

Passenger in a car that flipped and crashed on an exit ramp while fleeing

police officers

Passenger in a car that flipped and crashed on an exit ramp while fleeing

police officers

Passenger in a car that crashed into a concrete wall while fleeing police officers

Passenger in a car that crashed into a building while fleeing police officers Passenger in a car that crashed into a building while fleeing police officers Passenger in a stolen car that struck a pole while fleeing police officers Passenger in a stolen car that crashed into a ditch and overturned while fleeing police officers

Passenger in a car that careened into a light pole and flipped while fleeing police officers

Died in Accidental Collision with Police Vehicle $(\mathrm{N}=4)$

John Parham

Leo Blackmon Jr.

Stephen L. Tooson

Wendell Hall

Died in Prison $(\mathrm{N}=4)$

Christopher Lee Lucas

Matthew Walker

Robert Baltimore

Samuel Harrell
Accidental collision with a police cruiser that was en route to an accident Accidentally wrecked his ATV into a police cruiser Accidental collision with a police SUV that was responding to a call Accidental collision with a police cruiser

Prison inmate who died after fighting with another inmate

Prison inmate who died after being beaten by guards

Prison inmate who died after being placed in a restraint chair for $3+$ days Prison inmate who died as a result of injuries sustained during a fight with guards

Murder/Manslaughter by Off-duty Police or Correctional Officer ( $\mathrm{N}=14)$

Briant Paula

DUI manslaughter by off-duty police officer

Dason Peters 
Dylan Samuel-Peters

Jason Akeem Lewis

Jeremey Lake

Juan May

Justin Griffin

Keara Crowder

Kendall Alexander

Lana Morris

Montrell Moss

Quintine Barksdale

Vernicia Woodard

Wayne Wheeler
Infant shot by his mother, an off-duty police officer

Shot by off-duty correctional officer

Shot by his girlfriend's father, an off-duty police officer

Shot by off-duty police officer during a fight

Punched by off-duty police officer during a fight

Shot by her husband, an off-duty police officer

Shot by his wife, an off-duty police officer

Shot by her husband, an off-duty police officer

Shot by off-duty correctional officer during a road rage incident

Shot by off-duty police officer after he lunged at him in a dark parking lot and sloshed him with gasoline

Shot by boyfriend, an off-duty police officer

Punched by his neighbor, an off-duty police officer, during a fight

Died for Reasons Not Directly Attributed to Police Actions $(\mathrm{N}=13)$

Ariel Clark

Arvel Douglas Williams

Brian Acton

Gynnya McMillen

Jeffery B. Lilly Jr.

Kayla Moore

Kyam Livingston

Markus Clark

Samuel Dunn

Sandra Bland

Thomas Lane

Tyree Woodson
Jail inmate who was put in a restraint chair and ultimately died as a result of a blood clot in his lung

Died after swallowing cocaine while resisting police officers

Extremely intoxicated and caught in the act of assaulting and raping a woman; police officers were able to subdue him but he could not acknowledge their commands, and fell unconscious and died before EMS arrived

Died in her sleep at a juvenile detention facility as a result of sudden cardiac arrhythmia

Died after swallowing narcotics during a struggle with police officers

Died in custody; coroner attributed death to intersection of methamphetamines, codeine, cardiovascular disease, and obesity

Died in custody; coroner attributed it to an alcoholic seizure resulting from chronic alcoholism

Died on the way to the hospital after being arrested for assaulting a convenience store clerk; he fought with officers, but had a fever of 106.3 before he died, possibly as a result of using the drug "flakka"

Died in the back of a police van while waiting for the correctional facility to cease lockdown; he had ingested a latex glove filled with opiates the day before

Died of an apparent suicide while in jail

Died after crashing his vehicle into a tractor trailer; he resisted a fire fighter trying to extract him so violently that he broke the fire fighter's hand; a trooper tased him to get him to comply, but his death at the hospital was the result of injuries he sustained in the crash

Died of a self-inflicted gunshot wound to the head while in a bathroom stall at the police station 


\section{Armed or Attempted to Grab Police Firearm ( $\mathrm{N}=13)$}

Andre Milton

Anthony Dwayne

Harris

Antoine Dominique

Hunter

Cedric Stanley

D'Andre Berghardt Jr.

Dontre Bennett

Ezell Ford

Jason Harrison

Lavon King

Leroy Browning

Russell Lydell Smith

Steven Isby

Xavier Tyrell Johnson
Tried to run over a deputy with his car

Struggling for an officer's firearm; shot by backup officer

Tried to run over deputies with his car, then reached for a handgun before being shot

Struggling for an officer's firearm; shot by backup officer

Tasered while holding a flathead screwdriver; continued to resist and got into a state trooper's vehicle and reached for an AR-15 rifle before being shot by Bureau of Land Management officers

Shot after pulling a handgun on officers at the conclusion of a foot chase; witnesses claim he was unarmed and had his hands in the air Mentally ill man tackled an officer and attempted to grab his gun before officer's partner shot him

Video shows him advance toward officers with a screwdriver at close range Struggled for an officer's firearm

Struggled for an officer's firearm

Tried to run over officers with his car

Screwdriver

Passenger in a car that tried to run over officers

Toy Gun or Object that Resembled a Weapon $(\mathrm{N}=26)$

Arthur R. Williams Jr. Toy gun

Arteair Porter

Toy gun

Brian Day

Toy gun

Charlin Charles

Toy gun

Cortez Washington

Toy gun

David Andre Scott

Dennis Grisgby

Told SWAT team he was not coming out of his house without a fight; came out screaming and pointing a black object at officers, who shot and killed him; object turned out to be a small box shoved inside a black sock

Mentally ill man who had broken into a woman's garage; made an aggressive move toward officer with a 7 -inch metal object that appeared to be a knife; turned out to be the handle of a spoon

Dominique Silva

Toy gun

Donovan Thomas

Toy gun

India M. Beaty

Toy gun

John H. Crawford III

Toy gun

John T. Wilson III

Toy gun 


$\begin{array}{ll}\text { Kionte DeShaun } & \text { Toy gun } \\ \text { Spencer } & \text { Toy gun } \\ \text { Lamontez Jones } & \text { Toy gun } \\ \text { Leslie Sapp III } & \text { Toy gun } \\ \text { Lionel Gibson } & \text { Toy gun } \\ \text { Mark Anthony Blocker } & \text { Toy gun } \\ \text { Paul Gaston } & \text { Toy gun } \\ \text { Peter John } & \text { Toy gun } \\ \text { Richard Perkins } & \text { Toy gun } \\ \text { Robert Dentmond } & \text { Toy gun } \\ \text { Sherman Evans } & \text { Toy gun } \\ \text { Tamir Rice } & \text { Toy gun } \\ \text { Tiano Meton } & \text { Toy gun } \\ \text { Tyre King } & \text { Toy gun }\end{array}$

